III ENEI

Encontro Nacional de

Economia Industrial e Inovação
Indústria e Desenvolvimento Econômico:

desafios e perspectivas

18 a 20 de setembro de 2018

Uberlândia - Minas Gerais

\title{
COMPETIÇÃO TECNOLÓGICA EM ÁGUAS PROFUNDAS
}

Autores: Cássio Garcia Ribeiro ${ }^{1}$ e Stevan Bernardino Silva² .

Resumo: De acordo com a análise da literatura especializada, a tomada de decisão das companhias de petróleo sobre qual modelo de plataforma utilizar em cada campo se apoia principalmente em critérios técnicos - tais como Lâmina d'Água (LDA), profundidade do reservatório, condições ambientais etc. - e econômicos - tais como preço do petróleo e custo da plataforma, do sistema submarino e de manutenção. O objetivo deste artigo é jogar luz sobre essas questões a partir da literatura concernente à competição tecnológica, trazendo à tona conceitos como paradigma e trajetória tecnológica, dependência da trajetória, lock-in e lock out e design dominante. A metodologia adotada se apoia em revisão bibliográfica e em entrevistas semi-estruturadas com especialistas do setor de petróleo e gás natural. Partindo dos conceitos utilizados pela literatura sobre competição tecnológica, é possível identificar um paradigma atual, marcado pela exploração e produção de petróleo com a utilização de plataformas. No âmbito desse paradigma há duas trajetórias: a completação seca e a completação molhada. Associados a essas trajetórias, estão em competição diferentes modelos/designs de plataformas, tais como: FPSO, SS, TLP e Spar. A plataforma FPSO representa o design dominante. A existência de externalidades de redes e os retornos crescentes de adoção associados a esse modelo de plataforma concorreram para a soberania alcançada por tal design. Pode-se considerar o sistema de processamento submarino, uma descontinuidade tecnológica, estando associado ao surgimento de um novo paradigma, pois a forma de se produzir petróleo seria alterada radicalmente.

Palavras-chave: competição tecnológica; águas profundas; petróleo; plataforma petrolífera.

\section{TECHNOLOGICAL COMPETITION IN DEEP WATERS}

ABSTRACT: According to the analysis of the specialized literature, the decision making of the oil companies on which platform model to use in each field is mainly supported by technical criteria-such as water depth, reservoir depth, Environmental conditions etc.-and economical - such as oil price and platform cost, submarine system, and maintenance. The purpose of this article is to play light on these issues from the literature regarding technological competition, bringing to the fore concepts such as paradigm and technological trajectory, dependence on trajectory, lock-in and lock-out and dominant design. The methodology adopted is supported by bibliographical review and in structured interviews with specialists in the oil and natural gas industry. Starting from the concepts used by the literature on technological competition, it is possible to identify a current paradigm, marked by exploration and production of oil with the use of platforms. Within this paradigm, there are two trajectories: dry completion and wet completion. Associated with these trajectories compete different models/designs of platforms, such as FPSO, SS, TLP, and Spar. The FPSO platform represents the dominant design. The existence of network externalities and the increasing returns of adoption associated with this platform model have been enduring the sovereignty achieved by this model. It can be considered the submarine processing system, a technological discontinuity, being related to the emergence of a new paradigm, because the way of producing oil would be radically altered.

Key words: technological competition; deep water; oil; oil platform.

\footnotetext{
${ }^{1}$ Professor do Instituto de Economia e Relações Internacionais (IERI) da Universidade Federal de Uberlândia (UFU).

${ }^{2}$ Aluno de Graduação do curso de Relações Internacionais da Universidade Federal de Uberlândia (UFU).
} 


\subsection{Inovações Sociais}

\section{JEL: O3 Innovation - Research and Development - Technological Change $\cdot$ Intellectual Property Rights; O33 Technological Change: Choices and Consequences $\bullet$ Diffusion Processes}

\section{Introdução}

O primeiro registro de exploração offshore remonta ao final do século XIX, em lâmina d'água ultrarasas (de até 30 metros). Entretanto, pode-se dizer que essa atividade ganhou de fato um grande impulso a partir dos choques do petróleo e dos sucessivos conflitos no Oriente Médio, desde a década de 1970 do século XX, os quais incentivaram a abertura de novas fronteiras exploratórias. Nesse contexto, as estruturas offshore evoluíram de simples torres de perfuração de madeira, instaladas próximas à costa, para robustas instalações, fabricadas em aço carbono e outras ligas, instaladas a vários quilômetros adentro do oceano.

Com as descobertas de petróleo em águas profundas, a indústria petrolífera deparou-se com a necessidade de desenvolver tecnologias mais adequadas para enfrentar esse desafio. As plataformas fixas são inutilizáveis em águas profundas. Isso ensejou a criação de ambiente de seleção que privilegiasse tecnologias mais confiáveis e econômicas. Desenvolveram-se, portanto, as plataformas flutuantes de produção, que se desdobraram em dois sistemas marítimos concorrentes: as plataformas flutuantes operadas com completação molhada e as plataformas flutuantes operadas com completação seca. Além desses, há um novo sistema em fase experimental - o chamado subsea to beach.

O objetivo deste trabalho é, portanto, analisar, mediante conceitos e casos atrelados à literatura que aborda o tema da competição tecnológica, a disputa tecnológica que tem lugar na produção de petróleo em águas profundas. A metodologia se apoia na análise da literatura que se debruça sobre o tema da competição tecnológica, apresentando conceitos centrais e situações concretas, a partir das quais os conceitos são aplicados. Além disso, este estudo conta com informações e análises obtidas junto a especialistas do setor petrolífero, ligados à COPPE e à Petrobras. A pesquisa de campo foi conduzida a partir de entrevistas presenciais com a aplicação de questionário semi-estruturado, com o intuito de captar a visão dos especialistas do setor acerca da disputa tecnológica entre os sistemas de produção offshore utilizados pelas companhias petrolíferas.

Este artigo conta com mais três seções além desta introdução. Na próxima seção será realizada uma incursão teórico-conceitual em torno do tema da competição tecnológica, destacando conceitos e fenômenos como, paradigma tecnológico, trajetória tecnológica, dependência da trajetória, lock-in, lockout e design dominante. Posteriormente, na seção 2, analisar-se-á a disputa tecnológica na atividade de produção de petróleo em águas profundas, destacando as duas trajetórias tecnológicas dentro do paradigma atualmente em voga (completação seca e completação molhada), os quatro modelos de plataformas utilizados (FPSO, SS, TLP e Spar) e a possibilidade de quebra de paradigma tecnológico representado pelo sistema subsea to beach. Utilizar-se-ão os conceitos referentes à competição tecnológica para entender a disputa tecnológica no setor offshore de petróleo.

\section{Referencial teórico}

\subsection{Paradigma Tecnológico}

O conceito de paradigma tecnológico está relacionado à emergência de uma nova tecnologia, que engloba todo o setor produtivo, ao suscitar referências inteiramente novas ao processo de produção. $\mathrm{O}$ paradigma tecnológico gera mudanças estruturais nos métodos produtivos, requerendo novos meios de regulação e novos formatos de negócio. Dosi (1982) esclarece que o paradigma tecnológico é um modelo e um padrão de solução de problemas tecnológicos selecionados, baseados em princípios originados das ciências naturais - especialmente do conceito de paradigma científico de Thomas Kuhn - e das tecnologias materiais selecionados. Acrescenta que a busca de soluções para certos problemas tecnológicos tende a 
concentrar-se em torno das soluções já conhecidas e nos esforços para melhorar os conhecimentos fundamentais para essas soluções.

Os paradigmas tecnológicos incorporam-se em uma perspectiva que identifica os problemas mais importantes, ao definir não só padrões e traços de pesquisa, mas também modelos de solução de problemas. Estes determinam, em certa conjuntura, a tecnologia material a ser empregada, as necessidades a serem atendidas e os preceitos científicos a serem trabalhados nas tarefas. Assim, o paradigma tecnológico não só pode ser um artefato físico, apto a ser aperfeiçoado, mas também um conjunto de heurísticas, que determina inovações futuras (CAETANO, 1998).

Desse modo, a evolução de várias tecnologias, consolidadas em processos e bens, originados de efetivas e latentes aplicações de determinado paradigma, para a solução de problemas do sistema produtivo, forma o que Dosi (1982) denomina de trajetória tecnológica. Essa análise considera uma percepção conceitual circular, que vai do paradigma tecnológico à trajetória tecnológica, e vice-versa, apresentando o paradigma tecnológico função basilar na evolução da trajetória tecnológica.

O caso ilustrativo de paradigma tecnológico, desenvolvido por Tigre (2005), diz respeito à evolução das Teorias da Firma segundo as mudanças tecnológicas ocorridas em três paradigmas. O primeiro é o da Revolução Industrial da Inglaterra, cuja economia norteou o comércio mundial no século XIX e serviu de fundamento para a elaboração da teoria econômica neoclássica. O segundo refere-se ao período fordista, nos Estados Unidos no início do século XX, cujo modelo de organização da produção ensejou as teorias da firma e a teoria da economia industrial. O terceiro, por fim, é o paradigma das tecnologias da informação, nos anos 1970 e 1980, cujo arcabouço teórico está fundamentado nas correntes evolucionistas e neo-institucionalistas.

O caso demonstra como a teorias econômicas reagiram ao processo de inovação tecnológica e organizacional na firma de cada paradigma. Isso significa que a cada nova teoria econômica um paradigma tecnológico havia-se estabelecido no setor. Desse modo, as teorias econômicas da firma foram analisadas de acordo com o contexto histórico, institucional e tecnológico no qual estavam sendo originalmente desenvolvidas.

\subsection{Trajetória Tecnológica}

A trajetória tecnológica, segundo Dosi, pode ser definida como o modelo de atividade normal de solução de problemas - determinado por um paradigma -, representando-se pelo movimento de trade-offs multidimensionais entre as variáveis tecnológicas que o paradigma define como relevantes. Ao analisar o desenvolvimento das tecnologias, nota-se que há modelos relativamente ordenados de inovações, isto é, trajetórias do desenvolvimento tecnológico resultantes de cada padrão de atividade solucionadora de problemas, ou de cada paradigma tecnológico.

A trajetória tecnológica constitui-se mediante um conjunto de possíveis direções tecnológicas, havendo trajetórias mais genéricas ou mais limitadas e outras mais fortes ou mais fracas. A trajetória será mais forte quando o conjunto de tecnologias alijadas por essa trajetória for maior. Há, também, expressiva possibilidade de que o progresso em certa trajetória tecnológica conserve características cumulativas, de sorte que futuros avanços se relacionem à posição que uma empresa ocupa, no que se refere à fronteira tecnológica existente, definida como o máximo nível a ser alcançado em determinada trajetória.

A literatura neo-schumpeteriana explica que a diversidade do ambiente de seleção, em que há um processo de seleção para a inovação das estratégias empresariais e da qualidade das instituições técnicas e científicas, pode explicar as distintas trajetórias tecnológicas. Segundo essa corrente, o aprendizado é cumulativo, dependente, portanto, de trajetórias passadas, indicando que a evolução de uma empresa é determinada pelas competências acumuladas e pela natureza de seus ativos específicos. Tais competências mudam em função das oportunidades tecnológicas (TIGRE, 2006).

As inovações radicais, originadas a partir de um novo paradigma, dependem de novas oportunidades engendradas por avanços científicos ou obstáculos intransponíveis, descobertos na evolução de certas trajetórias tecnológicas. A trajetória tecnológica é, portanto, o conjunto de características cumulativas e evolucionárias que influenciam o desenvolvimento e as mudanças experimentadas por tecnologias, no momento em que são difundidas e utilizadas na produção e nos serviços (OECD, 1992). 
É a partir de uma trajetória tecnológica que se pode criar uma dependência da trajetória (Path Dependence), o que torna um setor produtivo circunscrito somente a um número limitado de tecnologias. O conceito de dependência da trajetória relaciona-se à dinâmica tecnológica que é limitada pela condução dos eventos tecnológicos ocorridos no passado, diminuindo as opções tecnológicas no futuro (DAVID, 1985; ARTHUR 1988). David (2000) salienta que a dependência da trajetória diz respeito a processos dinâmicos causais irreversíveis, pois o objeto basilar é a compreensão da história como método de ramificação não reversível, em que custos de transição, para outra trajetória anteriormente desprezada, acumulam-se, tornando essa transição improvável. É, portanto, difícil compreender o motivo pelo qual certas tecnologias foram escolhidas, caso não se observem os eventos precedentes e o seu efeito sobre as escolhas tecnológicas existentes.

Um elemento fundamental para o entendimento da dependência da trajetória é a situação de retornos crescentes de adoção, em que o aumento na aplicação de uma tecnologia, na produção ou na distribuição de um produto e no número de adotantes dessa tecnologia eleva os benefícios de forma autoreforçativa (ARTHUR, 1989). Os retornos crescentes de adoção produzem o processo de auto-reforço ou feedback positivo, que dão rigidez estrutural a uma alternativa em detrimento de outras, na medida em que, no início da sequência temporal, eventos aleatórios propiciam vantagens sobre outras opções disponíveis. A partir desse processo, usuários da tecnologia permanecem dependentes da trajetória.

Brian Arthur (1989) expõe quatro características dos produtos intensivos em tecnologia e conhecimento, aptos a estimular a condição de retornos crescentes de adoção. A primeira refere-se aos altos custos fixos e de instalação, que inibem a replicação de certa estrutura ou certa configuração tecnológica, de sorte que somente um paradigma se torne hegemônico. A segunda diz respeito a produtos ou tecnologias que envolvem efeitos de aprendizagem, porquanto não só geram acumulação de experiência no processo produtivo, mas também implicam externalidades positivas, facilitando o desenvolvimento de novos produtos, a partir dos ganhos prévios auferidos em cadeias produtivas ou tecnologias convergentes. Tais conhecimentos obtidos favorecem a continuidade da utilização da tecnologia.

A terceira concerne a efeitos de coordenação ou externalidades de rede, visto que tal característica exige compatibilidade dos produtos e das tecnologias entre usuários, de maneira que todos adotem a mesma solução, aumentando a demanda pelo produto, o que gera vantagens de rede. As externalidades de rede ocorrem quando o valor de consumo de um bem ou um serviço é função crescente da quantidade de usuários que utilizam produtos ou serviços compatíveis. A quarta, por fim, relaciona-se às expectativas adaptativas, pois os agentes propendem a optar pela tecnologia vitoriosa, isto é, a mais difundida.

O exemplo clássico em que se verifica a dependência da trajetória é o caso do teclado QWERTY. Em 1867, Christopher Latham Sholes patenteou um desenho de máquina de escrever, cujo ponto de impressão era basicamente imperceptível ao datilógrafo, já que se localizava embaixo do carro de papel. O problema desse modelo era que o usuário não saberia quando uma tecla estava presa e, assim, continuaria a digitar, ao bater repetidamente a impressão da mesma letra no papel (BERNARDI, 2012).

Para reduzir a incidência dos choques das teclas, Scholes produziu o modelo QWERTY, que possuía menos chances de emperrar, pois as teclas para os pares mais comuns de letras bateriam em lados diferentes da máquina. Brevemente, outros modelos de teclado de máquinas de escrever mais eficientes e sem emperramento se tornaram disponíveis, como o DVORAK (chamada de DSK - Dvorak System Keyborad - que, ao ser testado, mostrou possuir desempenho superior, permitindo mais velocidade e menos falha na digitação). A configuração QWERTY já havia, entretanto, estabelecido liderança inicial de mercado. Pode-se afirmar que nesse caso foi decisivo o mecanismo de retornos crescentes, mediante o qual os ganhos de quotas de mercado geravam redução dos custos marginais, bem como, acumulação de experiência, em que o uso contínuo do QWERTY tornava mais eficiente e aumentava os custos de transição para novo teclado (BERNARDI, 2012).

A característica primordial do processo histórico, consoante David (1985), geradora da dependência da trajetória, é a situação de feedback positivo ou auto-reforço. Assim, Arthur e David concordam que os retornos crescentes é condição indispensável da dependência da trajetória. Arrow (2000, 2004) e Page (2006) negam, porém, que os retornos crescentes o são para essa condição.

Arrow observa, por sua vez, a condição de irreversibilidade de investimentos no caso do teclado QWERTY. Concorda que, nesse caso, há retornos crescentes; assevera, entretanto, que o elemento crucial 
para explicar a dependência da trajetória é a irreversibilidade, pois a acumulação de capital humano investido no aprendizado do teclado QWERTY era um investimento que inviabilizava a transição para novo teclado, não obstante já houvesse opções mais eficientes.

\subsection{Lock-in e Lock-out}

$\mathrm{Na}$ competição tecnológica, o conceito de lock-in é usualmente definido como o processo de estreitamento do raio de opções a somente uma tecnologia. As empresas são submetidas a um processo de dependência, em função de optarem por uma tecnologia. Essa dependência advém da dificuldade de trocar uma tecnologia por outra, em razão do envolvimento de altos custos de mudança - que podem ser financeiros ou de aprendizado - e dos eventos históricos que levaram à escolha da tecnologia (ARTHUR, 1989). Dessa forma, os usuários da tecnologia propendem a não adotar novos paradigmas tecnológicos, mesmo quando estes propiciam resultados, em termos de desempenho, aparentemente mais satisfatórios (DAVID, 1985; ARTHUR, 1989). Uma empresa com certa trajetória permanece, portanto, limitada às tecnologias e aos conhecimentos desenvolvidos, impossibilitando sua alteração, salvo pelo surgimento de novo paradigma e nova trajetória tecnológica.

Com o intuito de explicar e aprofundar a forma pela qual o processo de lock-in se desenvolve, retoma-se ao momento em que a escolha por determinado paradigma tecnológico foi definida. Após a mudança no paradigma tecnológico, isto é, quando a escolha já foi realizada, é improvável o retorno à situação anterior, resultando em irreversibilidade. Quando há irreversibilidade tecnológica, não é possível regressar à situação anterior, já que nova posição no progresso de uma trajetória foi alcançada. Nesse sentido, David (1985) assevera que o surgimento de soluções tecnológicas causa, eventualmente, padronização precoce em certas condições, como as de economias de escala, interdependências técnicas e irreversibilidade produzida por efeitos de hábito e aprendizagem.

Assim, a própria evolução de certa trajetória tecnológica induz à diminuição da quantidade de tecnologias em competição, porquanto somente uma tecnologia predomina sobre as demais, em razão dos rendimentos crescentes de adoção (ARTHUR, 1989). A tecnologia que se beneficia de mais adoção no início de determinada trajetória consegue possuir peremptória vantagem sobre as outras, visto que, embora possa não ser, necessária e potencialmente, a mais eficiente, a partir de certo estágio, torna-se dominante e tende a alijar as demais. Esse processo de redução de escolhas a somente uma tecnologia, como já mencionado, é o lock-in, e a predominância da tecnologia pode ser explicada pela adoção inicial.

Como corolário da situação de lock-in, o lock-out é definido como a circunstância na qual as tecnologias, que não lograram êxito inicial, são impedidas ou bloqueadas de entrar na disputa tecnológica, por serem incapazes de concorrer com a tecnologia vencedora (NARAYANAN; CHEN, 2012). Esta pode ser ainda inferior às tecnologias impedidas de concorrer, uma vez que a escolha tecnológica realizada, ao longo dos primeiros estágios da competição, tem forte componente de incerteza e desconhecimento acerca das qualidades e das propriedades de outras tecnologias.

O lock-out ocorre no momento em que uma tecnologia se torna vencedora, pois, tendo esta predominado na competição tecnológica, suas concorrentes acabam, consequentemente, afastando-se do mercado, em função de algumas variáveis da tecnologia vitoriosa. Essas variáveis podem ser as seguintes: o paradigma adotado, a forma pela qual a trajetória tecnológica se constituiu e os meios pelos quais o lockin gerou o alijamento das tecnologias concorrentes - sobretudo mediante rendimentos crescentes de adoção, retornos crescentes de escala e eventos históricos que condicionaram a escolha à tecnologia vencedora.

O caso ilustrativo da situação de lock-in e lock-out é o do carro a gasolina versus o carro elétrico. Carros a eletricidade, a vapor e a gasolina competiam, basicamente, em condição de igualdade, no início do século XX. Segundo Freeman e Soete (2008), não havia evidências de que o motor a combustão interna - a gasolina - seria preferível em relação ao motor a vapor ou ao motor a eletricidade, visto que as inovações básicas no setor ocorreram simultaneamente. Os automóveis movidos a gasolina tornaram-se, entretanto, mais populares, pois possuíam mais autonomia que outros. Consequentemente, os carros a gasolina dominaram o mercado, alijando os carros a vapor e a eletricidade a nichos especializados.

O ostracismo do motor a eletricidade explicou-se pela questão da deficiência na infraestrutura de abastecimento de carros a eletricidade, tornando este óbice significativo para os usuários. Nas áreas 
urbanas, havia mais eletricidade, ao passo que nas áreas rurais, não. Assim, a utilidade dos carros elétricos se restringiu às áreas urbanas, enquanto a locomoção entre cidades ficou a cargo dos carros movidos a gasolina (MARTINS, 2015).

Além disso, Foray (1997) argumenta que a ausência de uma rede de abastecimento e distribuição de energia elétrica foi um dos importantes fatores inibidores do desenvolvimento e da difusão dos automóveis a eletricidade. O resultado poderia, entretanto, ter sido diferente, ao longo do tempo, na medida em que uma rede de postos de gasolina também teve de surgir para viabilizar o padrão efetivamente adotado - o motor a combustão. Nesse sentido, a formação da indústria do petróleo limitou as eventuais pesquisas que poderiam solucionar as deficiências dos carros a eletricidade.

Com a evolução dos investimentos no carro a gasolina, gerou-se a situação de lock-in na tecnologia do motor a combustão em detrimento do motor elétrico. Este foi afastado do mercado, entrando em uma situação de lock-out. O lock-in resulta em retornos crescentes de adoção da tecnologia, em consequência das inovações incrementais contínuas, proporcionada pelas externalidades de rede. Assim, observa-se que uma vez iniciada a trajetória tecnológica, foi mais fácil permanecer na trajetória escolhida do que mudar para outra. No caso dos veículos automotivos, os postos de gasolina favoreceram a adoção dos carros com este combustível (MARTINS, 2015).

Quanto à indústria de automóveis e à situação de lock-in, no que concerne ao carro a gasolina, qualquer mudança para um sistema alternativo, no caso para carros a eletricidade, tornava-se incerto. Ademais, os interesses específicos e os ganhos já consolidados da indústria do petróleo e da cadeia produtiva dos carros a gasolina afastaram os carros a eletricidade dos investimentos do setor automobilístico (MARTINS, 2015).

Dessa forma, a crescente disponibilidade de postos de abastecimento, associada à redução contínua do preço do petróleo, favoreceram a conquista do mercado pelos carros a gasolina. Este tornou-se, portanto, o paradigma tecnológico da indústria automotiva. A tecnologia para veículos elétricos não desapareceu, todavia, estabelecendo-se em outros veículos funcionais, como empilhadeiras e carros de golfe.

Atualmente, entretanto, em função do avanço tecnológico e das mudanças ambientais, a utilização do carro elétrico tem ganhado cada vez mais visibilidade. A matriz energética do petróleo, no que concerne à utilização do carro à combustão, ainda é predominante, mas vem relativamente perdendo espaço para a matriz elétrica, que não usa combustível fóssil, colaborando para a redução dos danos no meio ambiente, conforme aponta Roberto Max, da Fundação Vanzolini (LESSA, 2011). Recentemente, o transporte à combustão é responsável por volta de $23 \%$ da energia relacionada à emissão mundial de dióxido de carbono, com expectativa de aumento para $46 \%$ até 2050. É nesse cenário que o transporte elétrico aparece como uma alternativa para o setor de veículos motorizados (WEF, 2018).

Ressalta-se ainda que há três relevantes tendências modificando a gestão da cadeia de logística do setor automotivo: a eletrificação, a descarbonização do transporte, a direção autônoma e a conectividade de automóveis (HRUSECHÁ, 2016). Isso significa que toda a cadeia produtiva que fornece os elementos necessários aos carros à combustão terá de se modificar e se adequar as novas necessidades dos automóveis elétricos, desde as mudanças na estratégia de mercado dos postos de gasolina, oferecendo estações de abastecimento elétrico, até a inovação na fabricação de novas baterias para o uso nos veículos e no planejamento urbano.

Por fim, para que haja mudanças substantivas de paradigma no setor automotivo, não basta somente o esforço do setor privado em relação ao progresso tecnológico e as exigências ambientais. Políticas governamentais de incentivo são necessárias para auxiliar na facilitação da substituição de paradigma, visto que os custos de mudança da cadeia produtiva de automóveis envolvem toda a logística e a economia de um país, sobretudo se este tiver forte relação com o setor petrolífero (BARASSA, 2015). Assim, embora o carro elétrico tenha ganhado relativo espaço nas últimas décadas, ainda se depende de esforços conjuntos entre setor público, privado, científico e comunidade civil para uma mudança efetiva na indústria automobilística. 


\subsection{Design Dominante}

O desenvolvimento das inovações tecnológicas é uma constante na análise acerca da sobrevivência de empresas em mercados competitivos. Com o intuito de permanecerem competitivas, as empresas diferenciam-se mediante o lançamento de novas tecnologias e designs. A natureza competitiva somente finda na ocasião em que surge um design dominante, determinando, doravante, o paradigma tecnológico a ser seguido.

Para explicar o conceito de design dominante, é importante expor o modo pelo qual este se manifesta. No período inicial de desenvolvimento de uma tecnologia, há incerteza sobre as possíveis alternativas técnicas e as necessidades e as preferências dos consumidores. Dessa forma, a indústria procura atender a diferentes demandas dos usuários - ainda não totalmente inteligíveis - por meio de uma variedade de produtos e designs distintos. Nesse momento, enorme quantidade de inovações surge rapidamente. À medida que o desenvolvimento de uma tecnologia avança, tende a ocorrer interação entre a lógica interna de solução de problemas, existente em certa tecnologia, e a evolução da necessidade de seus consumidores; fato que conduz ao estabelecimento de um modelo de design dominante. A partir desse momento, a diversidade tecnológica começa a ser substituída pela padronização. (UTTERBACK; ABERNATHY, 1975)

Esse modelo de design, que estabelece estrutura hierárquica na evolução da tecnologia, é o que Utterback e Suárez nomeiam design dominante:

[...] um design dominante normalmente assume a forma de um novo produto (ou conjunto de características), sintetizado a partir de inovações tecnológicas individuais, introduzidas de forma independente em variantes de produtos anteriores. Um design dominante tem o efeito de reforçar ou incentivar a padronização, possibilitando que a produção e outras economias complementares possam ser buscadas. Portanto, a competição efetiva começa a desenvolver-se com base no custo e na escala, bem como no desempenho do produto (UTTERBACK; SUÁREZ, 1991, p.1).

Utterback e Suárez (1975) ainda asseveram que designs dominantes revelam, em certa medida, a consolidação dos padrões da indústria, assumindo a função de norteadores para mudanças vindouras no produto ou no processo e modificando a característica da inovação e da competição na indústria. Diminuem, consequentemente, a incerteza quanto à atividade de inovação e tornam mais seguras as expectativas tecnológicas e as de mercado.

Outros autores também contribuem para a caracterização do design dominante. Henderson e Clark (1990) asseveram que o design dominante é não somente definido por meio de conceitos de designs principais, os quais se referem às funções mais importantes realizadas pelo produto, como também é descrito por uma arquitetura de produto que determina a forma pela qual esses componentes se integram. Os pesquisadores Lee et al. (1995) tecem, por sua vez, suas considerações, expondo que o design dominante é o momento axial no desenvolvimento de uma inovação, ao assinalar a transição de um estado fluido para um específico, representando, assim, o ocaso do ciclo da seleção e da variação técnica. Inicia-se, doravante, uma era de maior incremento de desenvolvimento tecnológico.

O surgimento de um design dominante desloca a ênfase competitiva para favorecer outras firmas, aptas a alcançar alta capacidade no processo de inovação e integração, com o mais alto desenvolvimento interno técnico-científico. Dessa maneira, a ascensão de um design dominante marca o início do período de reorganização de uma indústria, de sorte que a incapacidade de certas indústrias de mudarem sua estrutura organizacional e suas práticas conduzi-las-á ao fracasso, já que não possuem recursos especiais para mantê-las no processo de transição do design dominante (UTTERBACK; SUÁREZ, 1991).

A ascensão de um design dominante é, portanto, resultado da interação entre escolhas técnicas e de mercado, que seguem determinada trajetória tecnológica; ou seja, o resultado decorre de uma série de decisões técnicas sobre o produto, concebido pelas escolhas técnicas prévias e pela evolução das preferências do cliente. Assim, um design dominante não apresenta, frequentemente, mudança radical, mas a síntese criativa da tecnologia disponível e o conhecimento existente acerca das preferências dos consumidores (UTTERBACK; SUÁREZ, 1991). 
Um caso conhecido sobre design dominante é o da disputa entre os formatos de videocassetes VHS (empresa JVC) e Betamax (empresa Sony). Cusumano, Mylonadis e Rosenbloom (1992) observaram que, no mercado de home video, o entrante pioneiro não possuía garantia de vantagem sustentável apenas por ter sido o primeiro, mas precisava de estratégia efetiva para aproveitar essa posição. Assim, a necessidade de ação estratégica era intensa, visto que outros entrantes, após analisar as reações dos usuários à oferta inicial do produto, podiam optar por escolher produto similar, com preços menores e com aspectos diferentes.

A empresa pioneira no desenvolvimento do videocassete foi a Sony, seguida pela JVC. A Sony não chegou a obter grande vantagem pelo fato de ter sido pioneira. Já, a JVC tinha como ponto mais forte o processo produtivo, estruturado para produzir em larga escala com preços muito menores, em função da economia de escala e da ampla rede de distribuição.

Nesse mercado, foram feitas manobras estratégicas que culminaram na formação de grupos de fabricantes e canais de distribuição alinhados para promover os formatos existentes. Não havia, até então, alinhamento de fabricantes de produtos complementares nesse setor. Com o aumento da demanda por fitas de video cassete e do número de produtores e locadores de fitas, houve o alinhamento destes agentes. Nesse sentido, Chiao (1999) observa que a externalidade de rede é variável crucial para a escolha do consumidor.

O BETAMAX estava, em termos de desenvolvimento tecnológico, à frente do VHS. Como líder nessa tecnologia, o BETAMAX preferiu não adiar a comercialização do produto, em vez de aguardar e comprometer-se a desenvolver um padrão com outras companhias. Assim, tornou-se mais inflexível quanto à mudança de design, pois as mudanças necessárias requeriam altos investimentos para novos equipamentos de fabricação, estimulando o lock-in deste modelo (FREEMAN; SOETE, 2000).

As alianças para o padrão VHS começaram a ser formadas, de modo que este pôde se beneficiar das redes de distribuição. A JVC, por um lado, com a política de agregar maior número de empresas para o VHS, concordava até que seus parceiros participassem do desenvolvimento de mudanças no formato do VHS. A Sony, por outro, não deu completa assistência aos parceiros e não possuía a mesma consistência e habilidade de negociação que a JVC para aliar mais fabricantes e canais de distribuição.

Ademais, a diferenciação de produto nesse mercado não foi primordial para o resultado da competição entre VHS e BETAMAX, pois qualquer inovação adicionada nos formatos era logo copiada e incorporada por outro. Havia apenas pequena vantagem da JVC por dispor de melhor estrutura produtiva que oferecia, para um mesmo modelo, mais combinações de itens que a Sony (CHIAO, 1999).

A vantagem inicial do VHS era mais capacidade de seu grupo de fabricantes de produzir mais do que o grupo do Betamax. A oferta de videocassetes VHS era maior, com mais facilidade para o consumidor de encontrar esse formato nos canais de distribuição, de sorte que a maior parte da indústria de fitas alinhouse ao formato VHS. Com o aumento da importância das fitas e a maior parte sendo lançada no modelo VHS, já se percebia a emergência do design dominante nesse segmento e a consequente situação de lockout do BETAMAX (ARTHUR, 1990).

Quando ainda não havia, inicialmente, rede de externalidades, com a demanda maior que a capacidade mundial de produção, os usuários tendiam comprarem qualquer um dos sistemas. À medida que um dos grupos de design começou a sobressair-se ao outro, os outros fabricantes que não aderiram a nenhum dos grupos optaram pelo que tinha mais possibilidade de se estabelecer, aumentando, a produção do VHS. Com mais produção e mais consumidores para o VHS, os fabricantes de fitas preferiram produzir nesse formato, de modo a praticamente excluir o formato BETAMAX (CHIAO, 1999).

\section{Disputa Tecnológica em Águas Profundas}

O uso de sistemas para a exploração de petróleo offshore ocorre não somente em situações desfavoráveis de instalação no fundo do mar, como também em longas distancias da costa marítima, recrudescendo os entraves no desenvolvimento tecnológico de equipamentos e sistemas para a exploração de petróleo em alto mar (MORAIS, 2013). Assim, a complexidade das atividades de exploração, desenvolvimento e produção de campos petrolíferos em alto-mar exige que decisões importantes sejam tomadas pelas companhias de petróleo. A primeira se refere à viabilidade da explotação da jazida, pois a 
confirmação de um reservatório não significa que será explotado. As empresas realizam, portanto, pesquisas pormenorizadas para obter informações como o tipo e a quantidade de óleo na jazida, de modo a assegurar a viabilidade do empreendimento.

Caso haja viabilidade, define-se o sistema de produção, que estabelece qual será o sistema de completação e a Unidade Estacionária de Produção ${ }^{3}$ (UEP). Em regra, o desenvolvimento da produção offshore em águas rasas ocorre em plataformas fixas, grandes estruturas (construídas com aço ou cimento) que repousam sobre o subsolo marinho. As plataformas fixas operam com completação seca, sistema constituído por um template ${ }^{4}$ que congrega várias cabeças de poço ${ }^{5}$, que são elevadas até a superfície por risers ${ }^{6}$ verticais rígidos, e as árvores de natal são colocadas no convés da plataforma.

Nas próximas subseções, analisar-se-ão, os seguintes sistemas de produção de petróleo em águas profundas: plataformas flutuantes com completação seca, plataformas flutuantes com completação molhada e o subsea to beach.

\subsection{Plataformas flutuantes com completação seca}

A princípio, antes de pormenorizar o sistema de produção de petróleo mediante plataforma flutuante com completação seca, há necessidade não só de distinguir brevemente as plataformas fixas das flutuantes, mas também explicar tecnicamente o termo completação. As plataformas fixas são aquelas apoiadas no fundo do mar, em que, independentemente do material utilizado em sua construção, não podem ser usadas em águas profundas por questão de custos crescentes - os quais aumentam exponencialmente conforme a profundidade -, ao passo que as plataformas flutuantes são estruturas complacentes posicionadas por sistema de ancoragem.

O termo completação, por sua vez, é utilizado para designar o conjunto de operações realizadas com vistas a equipar o poço para produzir óleo e gás. A completação consiste na instalação de diversos equipamentos tanto no interior como no exterior de um poço de petróleo, de modo a permitir que haja conexão segura e controlada entre o reservatório de hidrocarbonetos e a Unidade Estacionária de Produção. Tais equipamentos são responsáveis pelo controle da vazão dos fluidos e de funções auxiliares, como a elevação artificial do petróleo, a aquisição de dados e o controle da produção de areia (DEZEN, 2001).

O objetivo da completação é otimizar a vazão de produção (ou de injeção). Além disso, é importante que a completação minimize a necessidade de intervenções futuras para a manutenção do poço. Um poço é de completação seca quando a cabeça de poço e a árvore de natal estão posicionadas sobre a UEP, acima da superfície do mar, permitindo que a intervenção no poço seja realizada mediante sonda de superfície, instalada na própria plataforma. A conexão entre a árvore de natal e o poço ocorre por risers rígidos, ancorados nos equipamentos instalados no leito oceânico, implicando redução nos custos do projeto. Os modelos de plataformas TLPs (Tension-Leg Plataform) e Spars são operados com completação seca.

Nas plataformas TLPs, um dos componentes marcantes é seu sistema de ancoragem, constituído por tendões, ancorados no fundo do mar, lastreando a plataforma e conferindo rigidez no plano vertical a essa UEP (Figura 1).

\footnotetext{
${ }^{3}$ As Unidades Estacionárias de Produção, ou plataformas, são utilizadas para receber a produção de um ou mais reservatórios, para processar a produção dos poços de petróleo antes do escoamento da produção até os terminais apropriados (DEZEN, 2001).

${ }^{4}$ Conjunto de válvulas montadas no cabeçote do poço submerso que já está em produção.

${ }^{5}$ É a denominação dada ao conjunto de equipamentos que formam a arquitetura do poço.

${ }^{6}$ Cabos responsáveis por levar o óleo até a plataforma.
} 
Figura 1 - Plataforma TLP

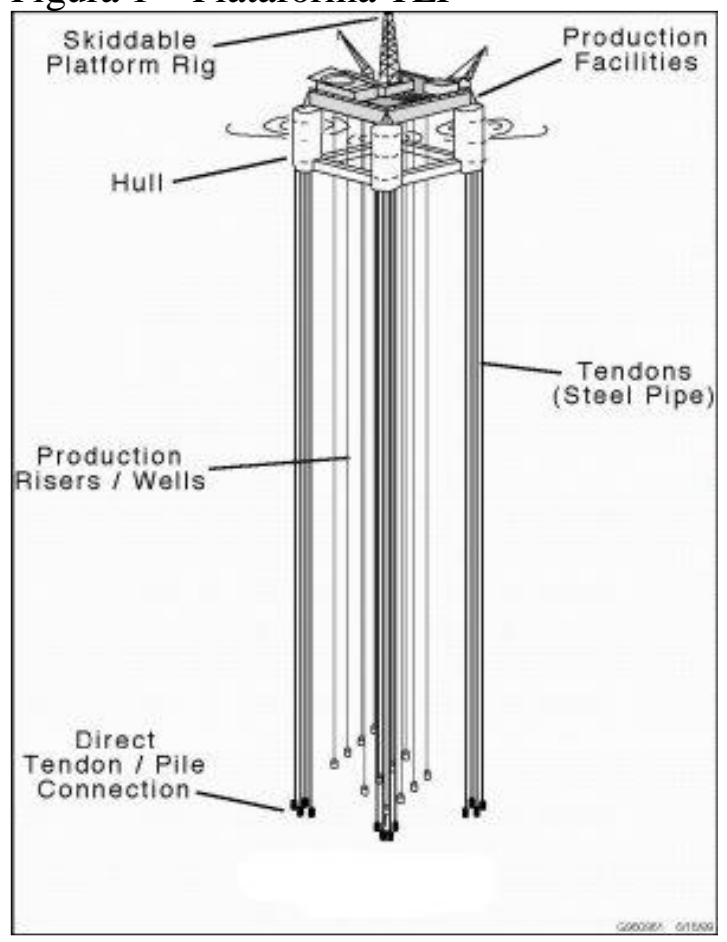

Fonte: Lacerda, 2007.

Quanto à plataforma Spar Buoy, esta é formada por um casco cilíndrico vertical de grande calado de até 200 metros. O sistema de amarração é baseado em âncoras e amarras espalhadas. A geometria da Spar permite que a amplitude de movimentos seja amortecida, gerando apenas pequenos movimentos verticais. Existem três tipos de Spar: a Clássica, a Truss e a Cell (Figura 2).

Figura 2 - Três principais tipos de plataforma Spar

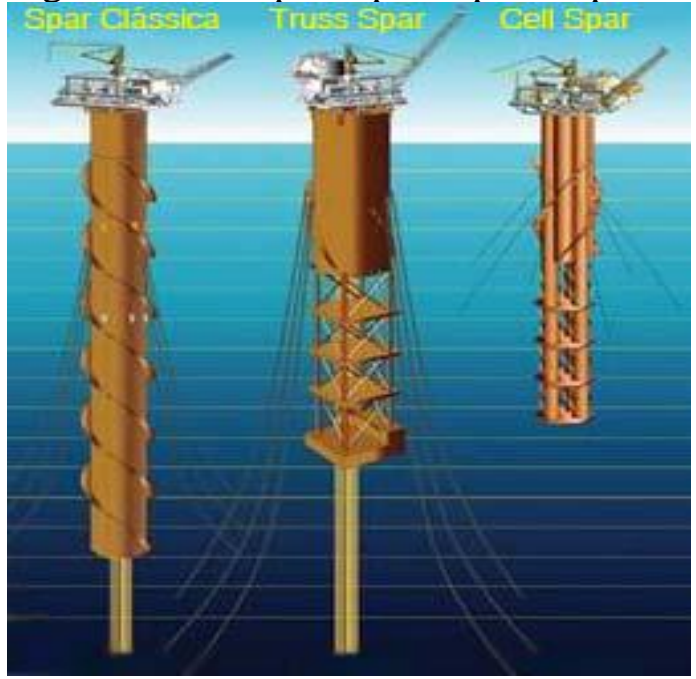

Fonte: Lacerda, 2007.

Observa-se, portanto, que a principal vantagem da completação seca são os risers rígidos, utilizados, não raro, em plataformas mais estáveis, como as TLPs e as Spars - em águas profundas. Em plataformas de intensa movimentação, como as FPSOs, esse tipo de duto pode apresentar problemas estruturais nas regiões do topo e do solo submarino. Outro aspecto positivo dos risers rígidos é o baixo custo em relação aos risers flexíveis, pois, em águas profundas, o uso de risers flexíveis torna-se mais oneroso, por possuírem, sobretudo, comprimento suspenso maior. 
Outra vantagem da completação seca é o fato de poderem ser constituídas por equipamentos de perfuração (sondas permanentes). A adoção desses modelos de UEPs permite a perfuração de novos poços, com taxa de recuperação maior do que os antigos, de maneira que eles representam "uma fábrica de poços no meio do campo". Portanto, as plataformas com completação seca para águas profundas podem não só produzir petróleo, como também assumir a atividade de perfuração de novos poços.

\subsection{Plataformas flutuantes com completação molhada}

Quanto ao sistema de completação molhada, nessa modalidade o poço é perfurado e completado por uma unidade móvel de perfuração, denominada de Mobile Offshore Drilling Unit (MODU), a partir de técnicas de perfuração e completação submarina. A condução do óleo da árvore de natal molhada (ANM) à UEP ocorre mediante risers ${ }^{7}$ flexíveis. Assim, o sistema criado subverte a regra de que a árvore de natal deveria ser instalada no convés da plataforma, como ocorre na completação seca. Os modelos de plataformas semissubmersíveis (SS) e FPSOs são operados com completação molhada.

A plataforma semissubmersível (SS) representa o primeiro modelo de plataforma flutuante. Utilizada, inicialmente, na perfuração de poços, após algumas adaptações, passou a ser usada como unidade produtora nos Sistemas de Produção Antecipada (SPA). Companhias de petróleo como a Petrobras começaram a adotar plataformas semissubmersíveis em seus sistemas de produção permanente e, desde então, esse modelo de UEP passou a representar alternativa para a produção de $\mathrm{P} \& \mathrm{GN}$ em águas profundas.

As plataformas semissubmersíveis são estruturas compostas por um casco que suporta o deck-box (convés), o qual comporta os equipamentos, as facilidades de produção e os alojamentos. Esse casco navega com propulsão própria ou é rebocado até o campo em que a plataforma será instalada, sendo ancorado por um conjunto de linhas de amarração.

Figura 3 - Plataforma Semi-Submersível

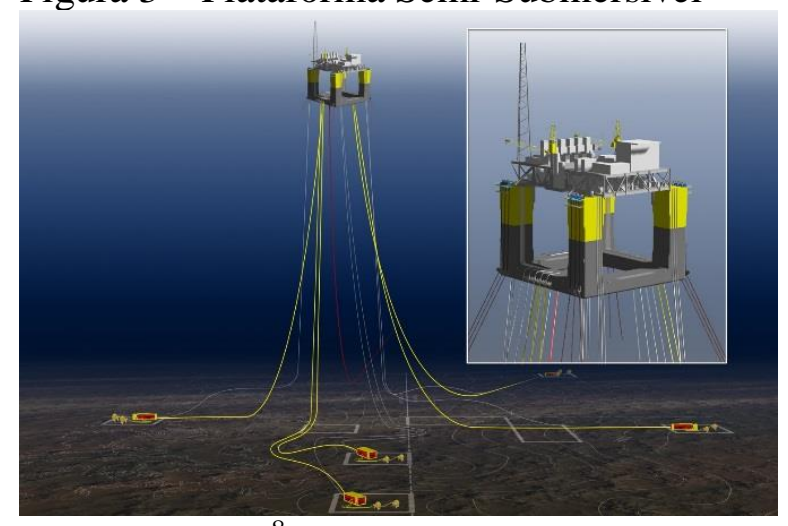

Fonte: Atlantia ${ }^{8}$

A grande vantagem desse modelo de plataforma é a possibilidade de aproveitamento de campos marginais ${ }^{9}$ e reservatórios dispersos em bacia marítima (FREITAS, 1993). Ressalta-se, entretanto, que as plataformas semissubmersíveis possuem praticamente nenhuma capacidade de armazenamento de produção e sua capacidade de carga também é bastante reduzida.

Outro modelo de plataforma com completação molhada é a Floating Production Storage and Offloading Unit (FPSO). Esta é uma adaptação de um navio petroleiro, sobre o qual se instala uma planta de produção. O FPSO fica posicionado sobre o poço, mediante âncoras, e os tanques do ex-petroleiro armazenam o óleo produzido, o qual é posteriormente escoado por navios aliviadores.

O sistema de amarração dessa plataforma é projetado para minimizar os problemas decorrentes dos esforços ambientais - ondas, correntes marinhas e vento - aos quais está sujeita. Algumas plataformas FPSOs também são equipadas com um sistema de posicionamento dinâmico. Este é constituído por

\footnotetext{
${ }^{7}$ Dutos responsáveis por levar o óleo até a plataforma.

${ }^{8}$ Disponível em: <http://www.atlantia.com/semisub/images/semisub_FPU.jpg> Acesso em: 22 jul. 2016.

${ }^{9}$ Campos cujo volume de produção não cobre os custos de produção.
} 
sensores acústicos, instalados na cabeça do poço e no casco da UEP, que emitem sinais para auxiliar na detecção de oscilações e movimentos da estrutura. Caso seja identificado desvio que comprometa as atividades da plataforma, os motores são acionados para restaurar a posição da unidade (FREITAS, 1993).

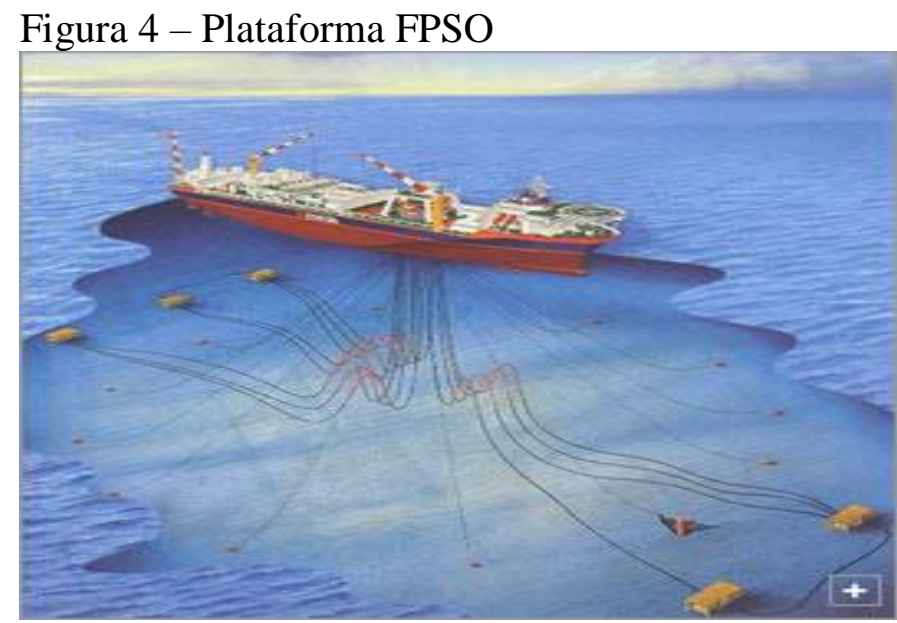

Fonte: Flexirisertest ${ }^{10}$

A adoção da plataforma FPSO concentrou-se em águas calmas e profundidades moderadas. Essa tecnologia foi, todavia, adaptada para a produção em águas profundas. Destaca-se certas vantagens de plataformas FPSO em relação a demais modelos de UEPs: grande área de convés e capacidade para receber peso; cronograma reduzido para conversão (caso sejam utilizados cascos de $\mathrm{VLCCs}^{11}$ ); custo de construção pouco sensível ao aumento da LDA; facilidade de remoção para o reaproveitamento em outros campos; e a expressiva capacidade de estocagem.

\subsection{Subsea to beach}

Com a intensificação da exploração de petróleo e gás em lâminas d'água ultraprofundas, os sistemas submarinos de produção tornaram-se imprescindíveis para o desenvolvimento de novos campos das operadoras de petróleo. Neste contexto, observa-se uma intensificação dos esforços direcionados ao processamento submarino do petróleo, na medida em que a indústria se torna mais confortável com diversas tecnologias.

Um reflexo importante da proliferação de sistemas submarinos mais complexos diz respeito ao aumento de unidades que operam de forma remota, interligadas em distâncias cada vez maiores. Esse processo resulta da conjunção de tendências importantes: a consolidação de sistemas de produção submarina crescentemente autônomos em relação ao apoio de plataformas na superfície do mar; o desenvolvimento de sistemas de geração e distribuição de energia elétrica no ambiente submarino; e sistemas de inspeção e manutenção de equipamentos submarinos mais sofisticados e autônomos (NETTO, 2016).

No conceito subsea to beach, a produção é escoada para uma unidade de processamento montada na costa. A exportação ocorre mediante arranjo submarino instalado no fundo do mar - uma equipe profissional controla, ao mesmo tempo, todo o processo em terra. A finalidade desse sistema é suprimir a utilização de unidades estacionárias de produção, viabilizando a produção de poços que antes não eram atrativos do ponto de vista econômico. Observa-se, nesse sentido, que a principal característica do modelo subsea to beach é a seguinte: a diminuição de homens no mar, gerando mais segurança no tocante aos aspectos operacionais da exploração (PORTO, 2013).

O subsea to beach utiliza tecnologias de separação, reinjeção e bombeamento submarino. Esse sistema permite o uso de plataformas menores, desabitadas, ou com o mínimo possível de pessoas a bordo ou, no limite, eliminando a necessidade da utilização de plataformas.

10 Disponível em: <http://www.flexirisertest.com/images/home_f_3.jp>Acesso em: 22 jul. 2016.

${ }^{11}$ No inglês, Very Large Crude Carriers. 
Figura 5 - Processo subsea to beach

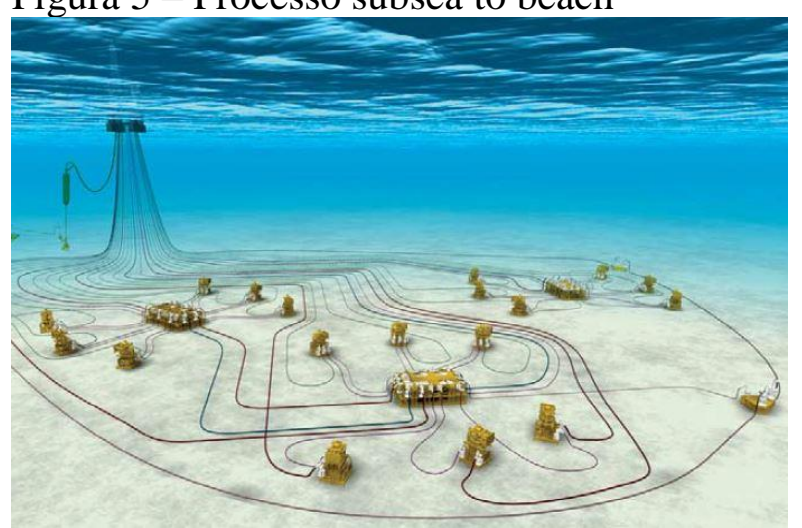

Fonte: Tecpetro ${ }^{12}$

Para viabilizar tecnologias independentes de unidades flutuantes, é necessário desenvolver potentes sistemas de bombeamento e métodos apropriados de separação submarina dos fluidos produzidos. Ademais, em relação à importância da viabilidade técnico-econômica do subsea to beach, inclui-se a necessidade de desenvolver formulações alternativas de dutos resistentes e com isolamento térmico, atendendo aos requisitos de projeto. Essa viabilidade deve levar também em consideração a instalação de cabos umbilicais elétricos e hidráulicos de transmissão de alta potência. Em função da característica da operação, a totalidade estrutural do sistema deve ser assegurada mediante métodos de averiguação submarina e análises de credibilidade dos equipamentos e do sistema integral (NETTO, 2016).

O conceito subsea to beach ou subsea to shore desenvolve-se com o intuito principal de ser alternativa às plataformas offshore. O alto custo de investimento de capital e o longo tempo necessário para a construção de novas plataformas, bem como os elevados custos operacionais das plataformas, favorecem a utilização do sistema subsea to beach, estimulando esforços tecnológicos para implementá-lo (PORTO, 2013). Todavia, a viabilização desse sistema encontra dois expressivos obstáculos: o tecnológico, que implica desenvolvimento de novos equipamentos submarinos e a garantia de escoamento na fase de produção, sobretudo quando se trata de escoamento multifásico.

Os equipamentos instalados no solo marinho podem, assim, tanto realizar pré-tratamento dos fluidos para depois bombeá-los separadamente (sistema de separação e bombeamento multifásico), como bombear a produção diretamente através de um sistema de bombeio multifásico. No sistema de separação e bombeamento multifásico são instalados equipamentos no fundo do mar, capazes de fazer a separação entre o óleo bruto e o gás natural, para em seguida encaminhá-los a uma plataforma instalada em águas rasas e/ou instalações em terra. No que diz respeito ao sistema de bombeio multifásico é instalada uma bomba no solo oceânico que permite o transporte a uma plataforma ou ao continente das misturas líquido/gás/sedimentos produzidos por um reservatório, prescindindo do processo de separação dessas misturas (PORTO, 2013).

Especialistas acreditam que novas tecnologias de bombeamento viabilizarão a construção de sistemas subsea to beach; este obstáculo, porém, contempla apenas parte do desenvolvimento tecnológico requerido para viabilizar tal sistema. Há outros desafios tecnológicos como a proteção anticorrosão, a injeção química, a prevenção de emulsão e a produção de água. São também necessários desenvolvimentos tecnológicos nas áreas de fornecimento de energia elétrica e separação de água e óleo (PORTO, 2013).

Malgrado haja óbices quanto à utilização do subsea to beach em curto prazo, a tecnologia pode implicar, em longo prazo, contenção econômica para as empresas petrolíferas, na medida em que os custos da instalação e da operação podem ser inferiores aos valores de sistemas convencionais. Essa nova tecnologia pode proporcionar produção em campos menores, visto que se torna desnecessário a instalação de uma plataforma em cada campo (NETTO, 2016).

\footnotetext{
${ }^{12}$ Disponível em: <https://tecpetro.com/2014/05/11/equipamentos-submarinos/> Acesso em: 22 jul. 2016.
} 


\subsection{A competição tecnológica na exploração de petróleo em águas profundas}

A princípio, quando se trata de exploração offshore de petróleo em águas profundas, constata-se o processo de lock-out relacionado ao uso de plataformas fixas. No setor offshore, as plataformas fixas são inutilizáveis em águas profundas, em função dos custos crescentes que aumentam conforme a profundidade. Não obstante representem um sistema tecnológico consagrado, as plataformas fixas não só possuem área de convés pequena, como também realizam as atividades somente em cerca de 300 metros de lâmina d'água. Assim, as plataformas fixas foram alijadas do processo de competição tecnológica em águas profundas pelas plataformas flutuantes, porquanto estas são econômica e financeiramente mais viáveis.

Apesar do alijamento das plataformas fixas da disputa tecnológica em águas profundas, observa-se que as trajetórias tecnológicas de completação molhada e seca coexistem em ambientes com esse perfil. Cabe observar que as companhias de petróleo, ao decidirem qual modelo de plataforma utilizarão em cada campo, consideram uma série de parâmetros, tais como: a lâmina d'água, a área do reservatório, o número de poços, a vazão diária por poço, as condições ambientais (ventos, ondas e correntes marinhas), o tipo de completação e a possibilidade de reutilização das plataformas. Após a análise em torno do volume de petróleo e gás recuperável e tendo sido identificado que o campo possui "acumulações potencialmente comerciais, iniciam-se estudos para avaliar a economicidade do campo e elaborar um plano de desenvolvimento de suas reservas" (Viegas, 2013, p. 135). Em tal etapa, são avaliadas questões atreladas ao ciclo de vida do projeto, tais como condições de operação, custos operacionais e de desativação.

Figura 6 - Modelos de plataformas utilizados em águas profundas pelas principais companhias de petróleo (2009)

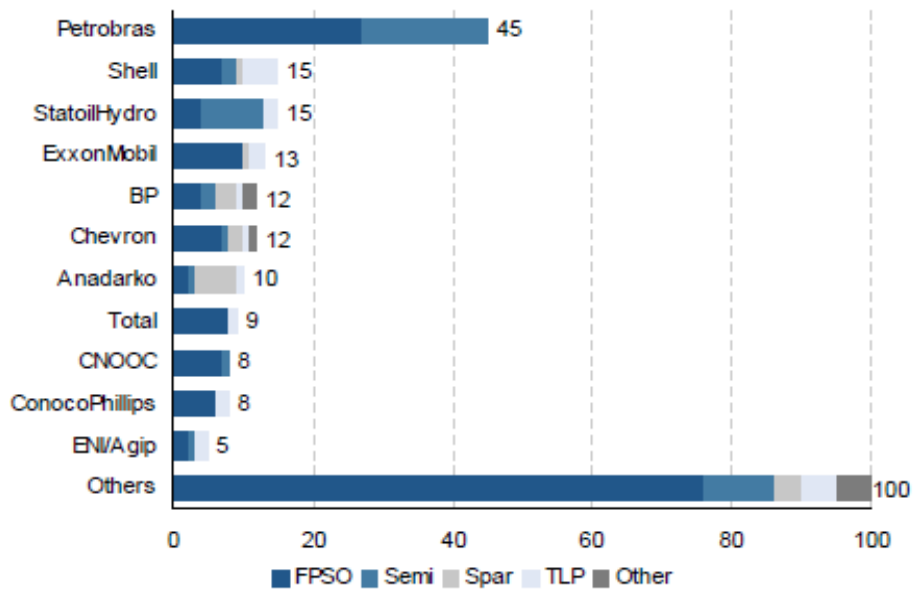

Fonte: PFC Energy.

Nota: Essas 15 operadoras contribuíam com 98\% da produção mundial em águas profundas em 2009.

A análise da Figura 6 evidencia o protagonismo das plataformas FPSOs. O grande número de companhias de petróleo usuárias desse modelo, bem como a criação de uma rede de fornecedores de equipamentos e serviços são elementos destacados pelos entrevistados para explicar o protagonismo da trajetória representada pela completação molhada. Em conjunto, ganhos de escala, redução de custos, curva de aprendizagem das companhias de petróleo e redução de riscos ambientais são componentes decisivos na competição tecnológica em águas profundas. Além disso, com base nas informações obtidas na pesquisa de campo, pode-se dizer que os grandes diferenciais desse conceito de plataforma em relação aos demais são sua grande capacidade de estocagem e seu custo de construção mais atrativo.

Em relação aos dados apresentados na Figura 6, chama a atenção a destacável atuação da Petrobras em águas profundas em comparação às demais companhias de petróleo listadas. A respeito da atuação da petrolífera brasileira cabe observar sua opção pela trajetória tecnológica de completação molhada. De acordo com as entrevistas realizadas, como os campos de exploração em que a Petrobras atua são, em geral, relativamente calmos e estáveis, tornou-se mais assertiva a escolha pela completação molhada, visto que as plataformas semissubmersíveis e FPSOs podem se posicionar longe do poço, o que favorece o aproveitamento de campos marginais e de reservatórios dispersos em uma bacia marítima. O predomínio 
das FPSO entre os dois designs de plataformas utilizados pela empresa, se justifica pela sua grande capacidade de armazenamento, o que representa vantagem considerável em relação às demais plataformas.

Alguns fatores contribuíram para reforçar a opção feita pela Petrobras pela trajetória tecnológica de completação molhada. Em primeiro lugar, por meio da utilização desse sistema foi possível superar os principais desafios impostos pelas águas profundas graças a uma gama de aperfeiçoamentos e modificações implementados nos sistemas de amarração e conexão, além do desenvolvimento tecnológico na área de completação submarina. Além disso, como a realidade financeira da Petrobras se agravou a partir da segunda metade da década de 1980, a estatal brasileira foi levada a prosseguir com sua estratégia incrementalista ao longo da década de 1990. Diante disso, a empresa engavetou seus conceitos próprios de plataformas semi-submersíveis e a opção por descontinuidades tecnológicas também perdeu espaço dentro da empresa. A restrição financeira que a Petrobras enfrentava a impeliu a partir para soluções mais econômicas. A substancial utilização de FPSOs, em comparação aos demais designs, contribui para que esse tipo de plataforma obtivesse mais flexibilidade em certas circunstâncias exploratórias e que fossem desenvolvidas adaptações e inovações incrementais. Isso permitiu redução de custos, melhoria da performance operacional e redução de riscos ambientais.

Figura 7 - Competição tecnológica em águas profunda (2017)

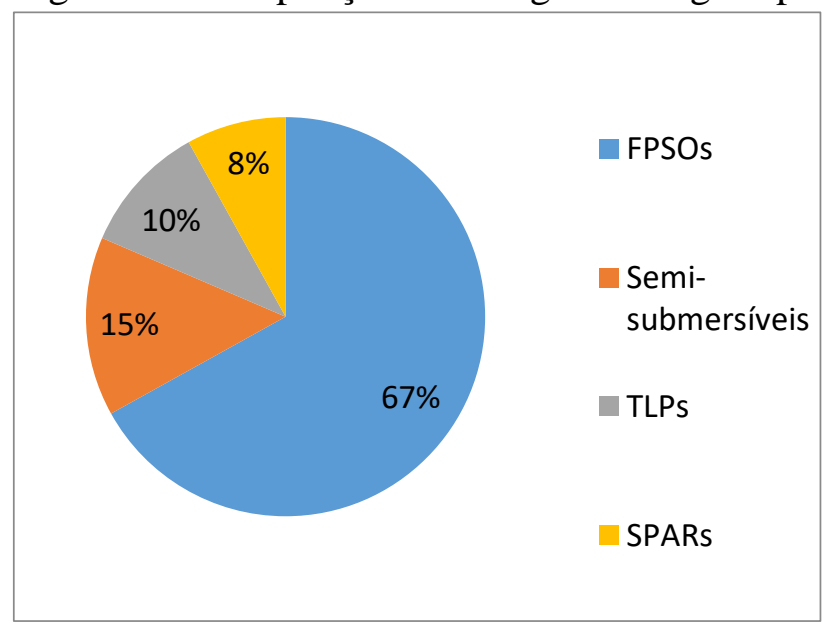

Fonte: Energy Maritime Associates (2017).

A partir da Figura 7 é possível perceber que não se alterou o quadro revelado pela Figura 6, ou seja, as plataformas de completação molhada se mantêm protagonistas na disputa tecnológica analisada neste artigo. No ano de 2017, do conjunto de plataformas utilizadas em águas profundas $67 \%$ (ou 166 unidades) eram FPSOs. O segundo posto nessa competição era ocupado pelas Semi-Submersíveis, design cuja participação era de 15\% (ou 36 unidades). Portanto, as plataformas de completação molhada representavam 82\% das unidades utilizadas pelas companhias de petróleo em águas profundas, em 2017.

Não obstante o protagonismo das plataformas operadas com completação molhada, particularmente das plataformas FPSOs, conforme se apurou na pesquisa de campo, essa trajetória tecnológica embute algumas desvantagens importantes vis-à-vis às plataformas operadas com completação seca, tais como: piores condições de estabilidades; inviabilizam a criação de um link físico da produção, da cabeça do poço até a superfície, de modo que a árvore de natal tem que ficar no fundo do mar, exigindo um grau de redundância maior para assegurar a segurança do sistema; como a árvore de natal fica longe do homem ela tem que ser preparada para intervenção à distância (a intervenção ocorre através de ROV), de forma que a arquitetura desse equipamento é significativamente mais complexa do que de uma árvore de natal seca (como ocorre nas plataformas operadas com completação seca).

$\mathrm{Na}$ disputa tecnológica no setor offshore, é difícil ocorrer o lock-in e o lock-out, porque se observa que as tecnologias, não raro, coexistem. Entretanto, quando uma empresa adota certa tecnologia, sobretudo aquelas que demandam alto investimento de capital, a dependência gerada pela trajetória tecnológica é expressiva, resultando em lock-in. Resta, todavia, saber o principal motivo da coexistência de tecnologias no setor offshore. Este elemento crucial é o aspecto ambiental. Uma empresa precisa conhecer bem as 
condições ambientais do campo de exploração, para que decida qual tecnologia utilizar. Se, por exemplo, o mar em que o campo se estabelece for calmo, pode-se implementar a completação molhada; se for, entretanto, mar agitado, deve-se empregar a completação seca, já que é desaconselhável o uso de FPSOs e semissubmersíveis em cenários marítimos adversos. Assim, uma empresa pode ter campos petrolíferos tanto em águas calmas, quanto águas agitadas, adotando concomitantemente as duas trajetórias tecnológicas e os quatro designs de plataformas analisados neste artigo.

Por fim, cabe avaliar as perspectivas em torno da quebra de paradigma tecnológico que representaria a concretização do modelo subsea to beach. A eliminação do uso de plataformas no desenvolvimento de reservatórios offshore traria uma grande economia de recursos, reduzindo os custos operacionais dos sistemas marítimos de produção, com pessoas e transporte.

Especificamente em relação à atuação da Petrobras em águas profundas, de acordo com informações coletadas na pesquisa de campo, as profundidades e distâncias em relação à costa fariam do pré-sal o laboratório perfeito para a aplicação dessas tecnologias. Ademais, tal opção representaria uma saída interessante para o problema da quantidade elevada de $\mathrm{CO} 2 \mathrm{em}$ muitos campos do pré-sal. Com base na adoção desse sistema tecnológico, haveria a separação e a reinjeção do CO2 no leito marinho, aumentando a produtividade dos reservatórios. Portanto, em virtude dos desafios impostos pelo pré-sal, como as grandes distância e profundidades e o alto teor de contaminantes ( $\mathrm{CO} 2$ e H2S) presentes nesse cluster, a quebra de paradigma traria importantes vantagens à empresa.

O uso de tecnologias de processamento submarino além de representar uma saída interessante para explotar os reservatórios do pré-sal, também constituiria, no médio e longo prazo, uma alternativa para a Bacia de Campos, pois com seu amadurecimento, a produção de água nos reservatórios desse cluster está aumentando. Nesse contexto, a plataforma que inicialmente foi projetada para receber 100 mil barris, com o passar dos anos continuará a receber esse quantitativo, mas com $70 \%$ de água e apenas $30 \%$ de óleo, por exemplo. Atualmente, a saída para a baixa taxa de recuperação dos poços antigos é seu fechamento e a abertura de novos, solução extremamente onerosa, sobretudo para as plataformas que não contam com sondas permanentes de perfuração. Assim, de acordo com um dos entrevistados, a melhor forma de resolver esse problema seria levar a planta de processo para o fundo do mar, "transformando água em óleo". Nesse sistema, a água produzida seria separada, tratada e descartada no fundo do mar, ou reinjetada no reservatório.

Apesar de toda euforia em torno das tecnologias de processamento submarino e da quebra de paradigma tecnológico como saída para os desafios do pré-sal, vale observar que essas tecnologias ainda estão, duas décadas após o lançamento dos primeiros projetos nessa área, em estágio experimental. Assim, alguns dos entrevistados apresentaram uma visão bastante cética acerca da viabilidade técnica do conceito subsea to beach, pois apesar das pesquisas nessa área já ocorrerem há muitos anos, os resultados até aqui foram infrutíferos.

\section{Conclusões}

A literatura que aborda o tema da competição tecnológica se apoia na ideia de que a realidade de muitos mercados é caracterizada pela existência de diferentes tecnologias que competem entre si na busca pela preferência dos consumidores, usuários ou clientes. Quando uma empresa se depara com mais de uma alternativa para o desenvolvimento de um projeto, a escolha da melhor opção passa pela avaliação das implicações que a adoção de cada alternativa teria para ela. Diante disso, a seleção dos critérios que serão utilizados no processo decisório representa um fator determinante para a escolha da melhor opção. De acordo com a análise da literatura especializada, a tomada de decisão das companhias de petróleo sobre qual modelo de plataforma utilizar em cada campo se apoia principalmente em critérios técnicos - tais como lâmina d'água, profundidade do reservatório, condições ambientais etc. - e econômicos - tais como preço do petróleo, custo da plataforma e do sistema como um todo (considerando a instalação de equipamentos subsea).

Partindo dos conceitos utilizados pela literatura sobre competição tecnológica, é possível identificar um paradigma atual, marcado pela exploração e produção de petróleo com a utilização de plataformas. No 
âmbito desse paradigma há duas trajetórias: a completação seca e a completação molhada. Associados a essas trajetórias, há diferentes modelos/designs de plataformas: FPSO, SS, TLP e Spar. A plataforma FPSO representa o design dominante. Evidencia-se a existência de externalidades de redes e os retornos crescentes de adoção associados ao uso da plataforma FPSO. O grande número de companhias de petróleo usuárias desse modelo, bem como a criação de uma rede de fornecedores de equipamentos e serviços certamente concorreram para o protagonismo desse design. Ademais, cabe salientar as vantagens das plataformas FPSOs concernentes aos quesitos capacidade de estocagem e custo de construção vis-à-vis aos demais modelos de plataformas.

Do ponto de vista da incursão teórica feita no artigo e aplicando-a à competição tecnológica em águas profundas, pode-se considerar o sistema de processamento submarino, uma descontinuidade tecnológica, estando associado ao surgimento de um novo paradigma, pois a forma de se produzir petróleo seria alterada radicalmente. Esses sistemas permitiriam o uso de plataformas menores, desabitadas, ou com o mínimo possível de pessoas a bordo ou, no limite, eliminariam a necessidade da utilização de plataformas, no conceito conhecido como subsea to beach.

Vale observar que a competição tecnológica pode assumir contornos diferentes, quando se analisa casos em que o usuário da tecnologia são empresas e não consumidores finais, na medida em que aquelas possuem mais condições de influir na disputa tecnológica que estes. Ao contrário dos consumidores que são basicamente tomadores de tecnologias, empresas usuárias de tecnologias utilizarão sua experiência tecnológica, poder de compra e poder de barganha para assegurar seus interesses e defender a viabilidade de seus empreendimentos. Essa perspectiva pode elucidar as razões pelas quais exista coexistência de tecnologias no setor offshore. Portanto, argumenta-se aqui que para compreender as decisões tecnológicas adotadas pelas companhias de petróleo, mais conservadoras, ou mais agressivas, guiadas por um comportamento incremental, ou por uma postura disruptiva, é importante compreender o comportamento do mercado petrolífero e as disputas pela apropriação da renda petrolífera.

\section{REFERÊNCIAS}

ABERNATHY, W. J.; UTTERBACK, J. M. A dynamic model of product and process innovation. $\begin{array}{llll}\text { Omega } & 3(6), & \text { pp.639-656. }\end{array}$ <http://scripts.mit.edu/ varun_ag/readinggroup/images/f/f6/Utterback_Abernathy__A_dynamic_model_of_process_and_product_innovation.pdf> Acesso em: 12 dez. 2015

ARROW, K. J. Increasing returns: historiographic issues and path dependence. The European Journal of the History of Economic Thought, v.7, n.2, p.171-180, 2000.

Path dependence and competitive equilibrium. In: GUINNANCE, T.; SUNDSTROM, W. A.; WHATLEY, W. C. (Eds.). History matters: essays on economic growth, technology, and demographic change. Stanford, CA: Stanford University Press, 2004.

ARTHUR, W. B. Competing technologies: an overview. In: Dosi G. Freeman C; Nelson R; Silverberg, G; Soete, L. (Eds) Techinal Change and Economic Theory, Pinter, London, 1988, 590-607.

BARASSA, Edgar, 1991- B231t Bar. Trajetória tecnológica do veículo elétrico : atores, políticas e esforços tecnológicos no Brasil / Edgar Barassa. Dissertação de Mestrado apresentada ao Instituto de Geociências da Unicamp - Campinas, SP : [s.n.], 2015.

BERNARDI, B. B. O conceito de dependência da trajetória (path dependence): definições e controvérsias teóricas. Perspectivas, São Paulo, v. 41, p. 137-167, jan./jun. 2012. <http://piwik.seer.fclar.unesp.br/perspectivas/article/viewFile/4978/4434> Acesso em: 12 nov. 2015. 
BRASIL. Economia e emprego: P-61 começa a operar no campo de Papa Terra. Disponível em: <http://www.brasil.gov.br/economia-e-emprego/2015/03/p-61-comeca-a-operar-no-campo-de-papa-terra> Acesso em: 22 jul. 2016.

CAETANO, R. Paradigmas e trajetórias do processo de inovação tecnológica em saúde.

Physis-Revista de Saúde Coletiva, v. 8, n. 2, p.71-94, 1998. <http://www.scielo.br/pdf/physis/v8n2/04.pdf > Acesso em: 20 dez. 2015.

CHIAO, S. C. Design Dominante: comportamento do consumidor e as estratégias de uma inovação tecnológica. São Paulo: EAESPIFGV, 1999. 117p. (Dissertação de Mestrado apresentada ao Curso de PósGraduação da EAESPIFGV, Área de Concentração: Mercadologia). $<$ https://bibliotecadigital.fgv.br/dspace/bitstream/handle/10438/5138/1199901390.pdf?sequence=1\&isAll owed=y> Acesso em: 12 jan. 2016.

DAVID, P. A. Clio and the economics of QWERTY. The American Economic Review, v.75, n.2, p.332337 ,

<http://www.colorado.edu/ibs/es/alston/econ8534/SectionVI/David,_Clio_and_the_Economics_of_QWE RTY.pdf> Acesso em: 04 jan. 2016.

Path dependence, its critics and the quest for historical economics. Working Paper, Department of Economics, Stanford University, 2000. Disponível em: < http://wwwsiepr.stanford.edu/workp/swp00011.pdf> Acesso em: 30 dez. 2015.

DEZEN, F. J. P. Opções reais aplicadas à escolha de alternativa tecnológica para o desenvolvimento de campos marítimos de petróleo. 2001. 100 f. Dissertação (Mestrado em

Ciência e Engenharia de Petróleo) $\square$ Faculdade de Engenharia Mecânica, Universidade Estadual de Campinas, Campinas.

DOSI, G. Technological paradigms and technological trajectories. Research Policy 11, North-Holland Publishing Company, 1982, pp. 147-162. Disponível em: $<$ http://citeseerx.ist.psu.edu/viewdoc/download?doi=10.1.1.319.868\&rep=rep1\&type=pdf $>$ Acesso em: 27 dez. 2015.

Technology, Industrial Structures and International Economic Performance: An Assessment of the State of the Art and some Suggestions for Future Study. Organization for Economic Co-operation and Development. Paris: Directorate for Science, Technology and Industry, 1982. 58 p. (mimeo).

Energy Maritime Associates (2017). Floating Production Industry 2017-2021 Outlook. Marine Money Offshore - Singapore, 16 de março de 2017. Disponível em: < https://www.marinemoney.com/system/files/media/2017-07/1505\%20MMO\%202017-EMA-

Floating\%20Production\%20Outlook\%202017-2021.pdf > Acesso em: 20 jul. 2018.

ENERGY MARKET RESEARCH. Floating Production Storage and Offloading (FPSO) Crucial Component of Early Production Facility, to Witness a CAGR of 11.2 \% during 2017-2023. Disponível em: https://globenewswire.com/news-release/2017/12/20/1267189/0/en/Floating-Production-Storage-andOffloading-FPSO-Crucial-Component-of-Early-Production-Facility-to-Witness-a-CAGR-of-11-2-during2017-2023.html. Acesso em: 06 jun. 2018. 
FONSECA, J. J. S. Metodologia da pesquisa científica. Fortaleza: UEC, 2002. <http://www.ia.ufrrj.br/ppgea/conteudo/conteudo-2012-1/1SF/Sandra/apostilaMetodologia.pdf> Acesso em: 01 dez. 2015.

FORAY, D. The dynamics implications of increasing returns: technological change and pathdependence inefficiency. International Journal of Industrial Organization, vol. 15, 1997, p. 733-752.

FREEMAN, C.; SOETE, L. The Economics of Industrial Innovation. The MIT Press, Cambridge, Massachusetts, Third Edition, 2000.

FREITAS, A. G. Capacitação tecnológica em sistemas para águas profundas: o caso da Petrobrás. 1993. 178 f. Dissertação (Mestrado em Política Científica e Tecnológica) - Instituto de Geociências, Departamento de Política Científica e Tecnológica, Universidade Estadual de Campinas, Campinas.

FURTADO, A. T, 1998. A trajetória tecnológica da Petrobrás na produção offshore. Recitec, v. 2 , n. 2. Recife.

GIL, A. C. Como elaborar projetos de pesquisa. 4. ed. São Paulo: Atlas, 2007. < https://professores.faccat.br/moodle/pluginfile.php/13410/mod_resource/content/1/como_elaborar_projet o_de_pesquisa_-_antonio_carlos_gil.pdf> Acesso em: 10 jan. 2016.

HENDERSON, R. M.; CLARK, K. B. Architectural Innovation: The Reconfiguring of Existing Product Technologies and the Failure of Established Firms. Administrative Science Quarterly, v.35, 1990, pp.9-30.

HRUSECHÁ, Monika SITÁROVÁ. The automotive industry on the brink of a new paradigm. Draft Information Report - European Economic and Social Committee, 2016.

Disponível em: <https://www.eesc.europa.eu/en/our-work/opinions-information-reports/informationreports/automotive-industry-brink-new-paradigm-information-report> Acesso em: 24 abril. 2018.

INMETRO. Inovação: principais conceitos. Disponível em: <http://inovacao.inmetro.gov.br/inovacaoprincipais-conceitos/> Acesso em: 27 dez. 2015.

\section{Monika SITÁROVÁ}

LACERDA, T. A. G., 2007. Análise de movimentos induzidos por vórtices em plataformas. Dissertação (Mestrado em Engenharia) - COPPE, Universidade Federal do Rio de Janeiro, Rio de Janeiro.

LEE, J.; O’NEAL, D.; PRUETT, M.; THOMAS, H. Planning for dominance: a Strategic Perspective on the Emergence of a Dominant Design. R\&D Management, 25, 1995, pp. 3-15.

LESSA, Rogério. Revista Rumos. Carro Elétrico - Revolução Silenciosa. Rio de Janeiro, 08 jul/ago 2011. Disponivel em: <http://www.abde.org.br/AssessoriaRevistaRumosInterno.aspx $? \mathrm{id}=333 \&$ titulo=Revista\%20Rumos\%20n \%C2\%BA\%20258> Acesso em: 24 abril 2018.

LÜDKE, Menga. \& ANDRÉ, Marli E. D. A. Pesquisa em educação: abordagens qualitativas. São Paulo: Pedagógica e Universitária, 1986.

MARTINS, C. N. Condicionantes da Difusão do Carro Elétrico no Brasil: análise dos fatores institucionais, econômico e técnicos, 2015, 222f. <http://www.ie.ufrj.br/images/posgraducao/pped/dissertacoes_e_teses/PPED_Tese_Claudia_Martins_Maro_de_2015.pdf> Acesso em: 16 nov. 2015. 
MORAIS, José Mauro de. Petróleo em águas profundas: uma história tecnológica da Petrobras na exploração e produção offshore. Brasília: Ipea: Petrobras, 2013. Disponível em: <http://www.ipea.gov.br/agencia/images/stories/PDFs/livros/livros/livro_petrobras_aguas_profundas.pdf $>$ Acesso em: 15 jul. 2016.

NARAYANAN, V.K.; CHEN, T. Research on technology standards: Accomplishment and challenges. Research Policy 41 (2012) 1375- 1406.

NETTO, Theodoro Antoun. Agendas tecnológicas setoriais (ATS): petróleo e gás. Disponível em: <http://www.abdi.com.br/Estudo/Panorama\%20Tecnologico\%20ATS_PeG.pdf> Acessado em: 22 jul. 2016.

OECD. ORGANISATION FOR ECONOMIC CO-OPERATION AND DEVELOPMENT. Manual de Oslo: diretrizes para coleta e interpretação de dados sobre inovação. 3. ed. Tradução de Finep. Rio de Janeiro: OCDE; Eurostat; Finep, $1997 . \quad$ Disponível em: <http://www.mct.gov.br/upd_blob/0026/26032.pdf> Acesso em: 01 jan. 2016.

OFFSHORE-MAG. FPSOs to continue market domination, report finds. Disponível em: https://www.offshore-mag.com/articles/2017/01/fpsos-to-continue-market-domination-report-finds.html. Acesso em: 06 jun. 2018

ORTIZ NETO, J. B.; SHIMA, W. T, 2008. Trajetórias tecnológicas no segmento offshore: ambiente e oportunidades. Revista de Economia Contemporânea, v. 12, n. 2, mai./ago., p. 301-332.

PAGE, S. E. Path dependence. Quarterly Journal of Political Science, n.1, p.87-115, 2006.

PETROBRAS, 2005. 30 years of deep water technology. Petrobras Magazine: International Communications - jun. 2005.

PETROBRAS, 2010. Plano de Negócios 2010-2014. Webcast. Disponível na internet em http://www2.petrobras.com.br/ri/port/webcast/presentation/webcast_pn-2010-2014.pdf, acessado em 07/09/2010.

PETROBRAS, 2016. Fatos e dados: Plataforma P-61 entra em produção em Papa Terra no RJ. Disponível em: <http://www.petrobras.com.br/fatos-e-dados/plataforma-p-61-entra-em-producao-empapa-terra-no-rj.htm> Acesso em: 22 jul. 2016.

PORTO, Anna Carolinna Carrano Henriques. Estudo de Implantação de Processamento Submarino com Exportação para a Costa. Rio de Janeiro: UFRJ/COPPE, 2013.

RIBEIRO, C. G. Compras governamentais e aprendizagem tecnológica: uma análise da política de compras da Petrobras para seus empreendimentos offshore. 2009. 306 f. Tese (Doutorado em Política Científica e Tecnológica) - Instituto de Geociências, Departamento de Política Científica e Tecnológica, Universidade Estadual de Campinas, Campinas.

TIGRE, P. B. Gestão da inovação: a economia da tecnologia no Brasil. Rio de Janeiro: Campus, 2006.

UTTERBACK, J. M.; SUÁREZ, F. F. Innovation, competition, and industry structure. Sloan School of Management, MIT, Cambridge, MA, USA, 1991. Disponível em: <http://people.bu.edu/fsuarez/Fernando_Suarez_Website/Publications_files/1993_RP_InnovationCompeti tion_Utterback_Suarez.pdf> Acesso em: 25 dez. 2015. 
WILLIAMS, N., LEVERETTE, S., 2009. Development of a dry-tree semisubmersible concept for ultradeepwater offshore Brazil. 4th International Workshop on Applied Offshore Hydrodynamics. 2 - 4 dec., 2009. Rio de Janeiro - Brasil.

World Economic Forum. How electric vehicles are the start of a global shift in our attitudes, 2018. Disponível em: <https://www.weforum.org/agenda/2018/04/not-so-fast-why-the-electric-vehiclerevolution-will-bring-problems-of-its-own> Acesso em: 24 abril 2018. 